Edisi Khusus Vol. 4 No. 3 (Desember 2021), Halaman: 247 - 256

Available Online at http://ejurnal.ubharajaya.ac.id/index.php/Jabdimas

\title{
Peningkatan Kapasitas Life Skill Pada Program Kewirausahaan Siswa SMK Pelita IV dan Kelurahan Tanjung Duren Utara
}

\author{
Saparso ${ }^{1}$, Melitina Tecoalu ${ }^{1}$, Bambang Siswanto ${ }^{1}$, Krisnawati Tarigan ${ }^{1}$, Daniel Widjaja ${ }^{1}$, \\ Rita Amelinda ${ }^{1}$, Olfien Riruma ${ }^{1}$, Hery Winoto $\mathrm{Tj}^{1{ }^{,}}$ \\ ${ }^{1}$ Fakultas Ekonomi dan Bisnis; Universitas Kristen Krida Wacana, Tanjung Duren Raya No.4 \\ Jakarta Barat 11470; 021-5666952; email: saparso@ukrida.ac.id, melitina@ukrida.ac.id \\ daniel.widjaja@ukrida.ac.id, Bambang.siswanto@ukrida.ac.id, krisnawati.tarigan@ukrida.ac.id, \\ rita.amelinda@ukrida.ac.id, olfien.riruma@ukrida.ac.id \\ * Korespondensi: e-mail: hery.winoto@ukrida.ac.id
}

Submitted: 15/12/2021; Revised: 18/12/2021; Accepted: 28/12/2021; Published: 31/12/2021

\begin{abstract}
Empowerment is the development of self-potential in meeting their own economic needs without the help of others. This is done with an entrepreneurship workshop to open the participants' horizons so that they have the same mindset about entrepreneurship. Through this workshop, the participants opened their horizons about the business opportunities around them. The community service carried out aims to develop the economic potential of the existing community and improve community skills and students have the drive and ability to create jobs for themselves and for the surrounding community. With several approaches in the implementation of abmas, it is intended that the participants are easy to accept and implement them in the community so that the target can be achieved in order to have skills and create new jobs as expected.
\end{abstract}

Keywords: Community Empowerment, Entrepreneurship, Life Skill Capacity

\begin{abstract}
Abstrak
Pemberdayaan adalah merupakan pengembangan potensi diri dalam memenuhi kebutuhan ekonominya sendiri tanpa bantuan orang lain. Hal ini dilakukan dengan workshop kewirausahaan untuk membuka wawasan para peserta agar memiliki mindset yang sama tentang entrepreneurship. Melalui workshop ini para peserta terbuka wawasannya mengenai peluangpeluang usaha yang ada di sekitarnya. Pengabdian masyarakat yang dilaksanakan ini bertujuan mengembangkan potensi ekonomi dimasyarakat yang ada serta meningkatkan ketrampilan masyarakat dan siswa memiliki dorongan dan kemampuan dalam menciptakan lapangan kerja sendiri dan untuk masyarakat sekitarnya. Dengan beberapa pendekatan dalam pelaksanaan abmas ini bertujuan agar para peserta mudah untuk menerima dan mengimplementasikannya di masyarakat sehingga target dapat tercapai guna memiliki ketrampilan dan penciptaan lapangan pekerjaan baru terlaksana sesuai harapannya.
\end{abstract}

Kata kunci: Pemberdayaan Masyarakat, Kewirausahaan, Kapasitas Life Skill

\section{Pendahuluan}

Masyarakat yang menghadapi kesulitan dalam memperoleh lapangan pekerjaan menjadi dampak buruk bagi kelanjutan kehidupan masyarakat tersebut. Yang akan terjadi adalah banyaknya penganguran karena lapangan kerja yang tersedia sedikit dan permintaan kerja yang banyak sehingga mereka pasrah dan memilih menjadi pengangguran. Adanya Program Merdeka 
Saparso, Melitina Tecoalu, Bambang Siswanto, Krisnawati Tarigan, Daniel Widjaja, Rita Amelinda, Olfien Riruma, Hery Winoto Tj

Belajar Kampus Merdeka (MBKM) memberikan kesempatan siswa untuk belajar secara langsung dengan praktisi yang berkompeten di bidangnya, sehingga mereka dapat mengekplorasi pengetahuan (knowledge) dan keahliannya (skills) dalam mengimplementasikannya pada industri maupun lingkungan masyarakat. Generasi muda merupakan generasi yang berperan menjadi penerus bangsa dimana mereka harus memiliki kemampuan untuk dapat melihat peluang jauh kedepan (visioner) akan suatu situasi serta kebutuhan dari negerinya. Aspek tersebut salah satunya wajib dimiliki oleh seorang wirausaha (Nagel, 2016). Menurut Istianti (Tecoalu et al., 2021) Peran wirausaha sangat dibutuhkan sebagai pendorong perubahan kemajuan perekonomian suatu negara sebagai salah satu inovasi, oleh karena itu Merdeka belajar dalam arti sekolah, guru-guru, dan muridnya, mempunyai kebebasan dalam berinovasi dan bertindak dalam proses belajar mengajar.

Pendekatan model pembelajaran seperti itulah yang kedepannya akan dianut, karena perkembangan teknologi dan dampak covid-19 sangat berpengaruh terhadap lingkungan bisnis dan lapangan pekerja sesuai yang tersedia. Hal itu menuntut sekolah maupun kampus lebih kreatif dalam proses mengajarnya. Fokus belajar juga harus dirubah tidak pada teori tetapi pembekalan-pembekalan praktis. Salah satu materi ajar yang pendekatannya lebih mudah diimplementasikan adalah pembelajaran dibidang kewirausahaan.

Menurut (Dewi et al., 2015) pendidikan kewirausahaan dapat dilaksanakan secara terpadu dalam proses pendidikan di sekolah dengan berbagai kegiatannya. Mental calon wiraswasta yang mandiri, kreatif, dan inovatif merupakan modal dasar yang perlu dikembangkan oleh para calon wirausaha tersebut ketika mereka ingin memulai kegiatan berwirausaha (Saparso et al., 2017). Lebih lanjut pada Penelitian yang dilakukan oleh (Nurlela et al., 2017) di SMA Purworejo dan (Heriansyah et al., 2020) di SMAN 1 Sungai Ambawang, menunjukkan bahwa $80 \%$ lebih para siswa setelah lulus berminat untuk berwirausaha. Dimana hal ini dipengaruhi oleh adanya mata pelajaran kewirausahaan yaitu pembelajaran praktek berwirausaha terhadap minat berwirausaha (Achad, 2017). Menurut (Iswandari, 2013) pengetahuan berwirausaha merupakan segala yang berhubungan dengan data dan dijalankan dengan bentuk memori dan pengertian serta bagaimana melakukannya sehingga dapat membuat keberanian dalam menerima segala bentuk risiko dan berhati - hati dalam menjalankan keinginannya tersebut. Sedangkan (Suryana, 2013) berpendapat yang menjadi alasan atau motivasi seseorang untuk berwirausaha adalah: alasan keuangan, alasan sosial, alasan pelayanan, dan alasan pemenuhan diri. Sehingga dengan satu atau beberapa alasan yang tersebut tadi akan memperkuat para pelajar untuk senantiasa berjuang baik sebagai pelajar, anak bagi orang tuanya dan kelak menjadi masyarakat pada umumnya.

Entrepreneur yakni ialah seseorang yang mampu menciptakan pekerjaan maupun usaha, dimana berani mengambil risiko ketika menghadapi suatu kondisi ketidakpastian dimana mereka memiliki keberanian untuk mengelola hal tersebut menjadi peluang bisnis, tentunya dengan mengkombinasikan sumber daya yang ada (Wibowo, 2011). Pola pikir seorang 
entrepreneur (entrepreneur mindset) merupakan pola pikir yang menciptakan suatu nilai yang berbeda serta peluang yang dapat mendorong terciptanya kreativitas dan inovasi. Hal tersebut tentunya dapat menciptakan keunikan bagi seorang entrepreneur. Pola pikir tersebut dapat mendorong seseorang agar dapat menyikapi suatu situasi dengan melakukan sikap yang berbeda terhadap usaha yang akan dijalaninya (Ma \& Tan, 2006). Kemampuan dari seorang entrepreneur untuk menciptakan sesuatu yang inovatif serta unik merupakan inti dari proses kewirausahaan itu sendiri. Hal tersebut tentu dapat menciptakan peluang usaha bagi diri sendiri maupun banyak orang (Indra et al., 2019). Sisi positif yang terbentuk dari seorang entrepreneur dapat memberi manfaat positif bagi lingkungan sekitar, seperti penciptaan lapangan pekerjaan ataupun sebagai penyedia sumber daya bagi masyarakat (Halim et al., 2019).

Program ini merupakan kegiatan implementasi hibah dari Dikti dalam pengabdian kepada masyarakat berbasis hasil penelitian dan purwarupa PTS yang dilaksanakan dalam meningkatkan minat kewirausahaan generasi muda pada siswa SMK Pelita IV Jakarta yang memiliki motivasi untuk menambah ketrampilan serta berniat menciptakan lapangan pekerjaan. Karena banyaknya lulusan peserta didik yang setelah lulus mencari pekerjaan Rata-rata setiap tahun yang tertampung pada lapangan kerja yang tersedia hanya $\pm 45,5 \%$. Selain itu juga melakukan program pemberdayaan masyarakat di Kelurahan Tanjung Duren Utara Jakarta Barat. Pengembangan program peningkatan kapasitas Life Skill dalam rangka pengembangan program kewirausahaan memerlukan dukungan dari berbagai pihak, baik dunia industri, Perguruan Tinggi serta masyarakat. Universitas Kristen Krida Wacana (UKRIDA) melalui Lembaga Pengabdian Masyarakat memiliki peran strategis dalam rangka membantu mengembangkan sekaligus berkontribusi dalam mewujudkan program kewirausahaan. Dengan bantuan pengembangan program, pendampingan. serta memberikan akses layanan dari pemerintah merupakan langkah strategis dalam rangka percepatan / akselerasi program kewirausahaan pada masyarakat. Ini juga merupakan implementasi dari Merdeka Belajar Kampus Merdeka (MBKM) yang dilakukan oleh UKRIDA.

\section{Metode Pelaksanaan}

Dalam kegiatan ini adalah masyarakat, siswa dan guru SMK Pelita IV Jakarta dan kelurahan Tanjung Duren Utara Jakarta Barat. Adapun metode pelaksanaannya diantaranya dilakukan secara webinar, daring dan pendampingan.

Webinar dilakukan dengan menghadirkan pakar di setiap bidang untuk memberikan pemahaman kepada setiap peserta yang hadir dalam kegiatan ini. Diskusi dilakukan untuk mengajak para peserta ikut aktif didalam proses ini, sekaligus untuk mengetahui pemahaman setiap peserta workshop, dimana peserta khususnya dari masyarakat memiliki latar belakang Pendidikan dan pengalaman yang berbeda-beda. Kegiatan pendampingan ini dilakukan tidak hanya sampai pada tahap workshop saja tetapi sampai pada tahap implementasi. Pendampingan dilakukan sampai para peserta siap dan mampu untuk melakukan bisnis. 
Tabel 1. Acara Kegiatan Workshop

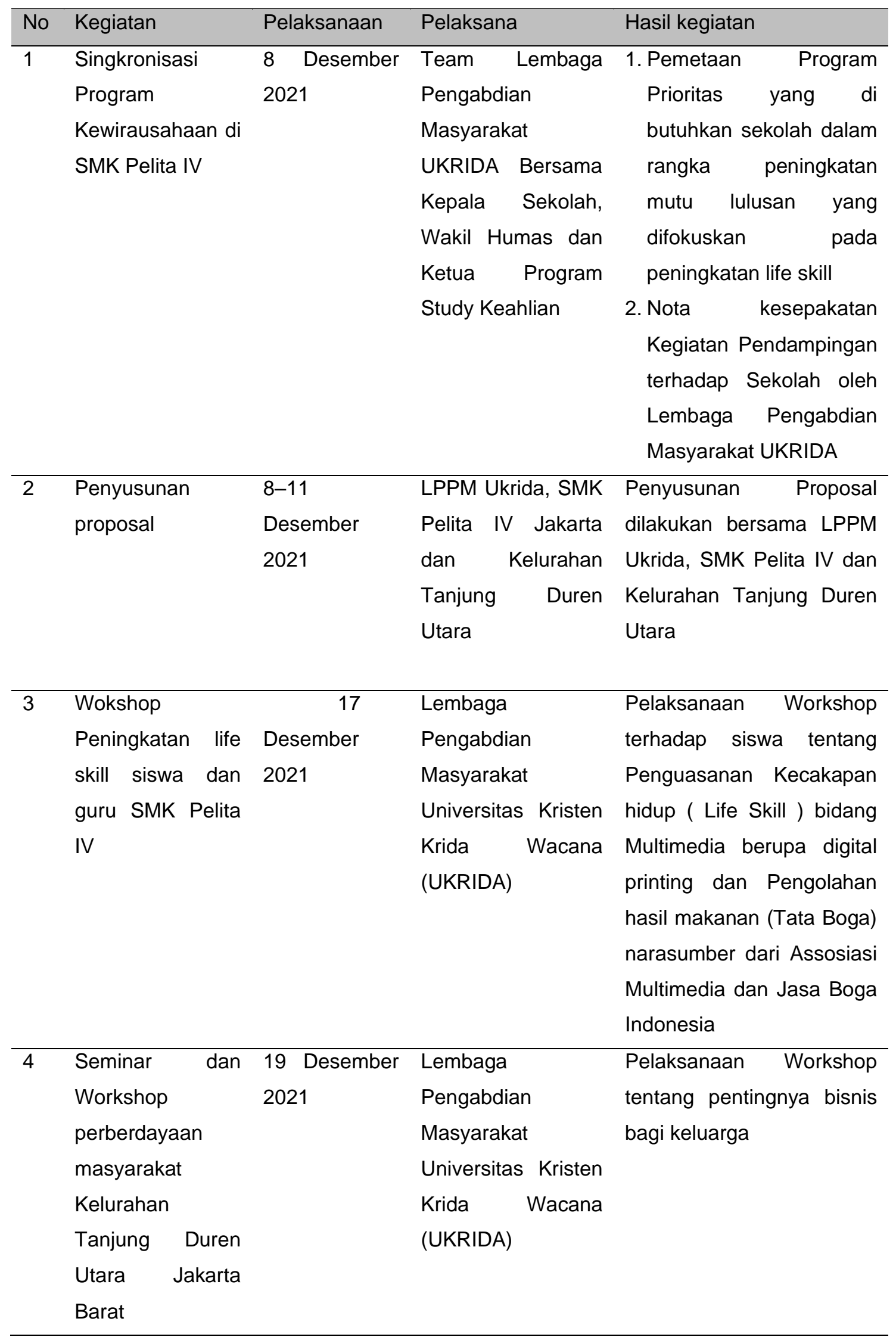




\begin{tabular}{lllll}
\hline 5 & Pendampingan & $20-21$ & Lembaga & 1. Proposal usaha \\
& $\begin{array}{l}\text { Program } \\
\text { Kewirausahaan }\end{array}$ & Desember & Pengabdian & 2. Program Kegiatan \\
& 2021 & Masyarakat & Usaha Sekolah \\
& & Universitas Kristen & 3. Tata Kelola usaha \\
& & Krida Wacana & rumahan atau UMKM \\
& & (UKRIDA) & \\
\hline $6 \quad$ Tindak Lanjut & $3-31$ Januari & Lembaga & Pendampinganpengelolaan \\
& pengembangan & 2022 & Pengabdian & dan pengembangan usaha \\
& usaha & Masyarakat & \\
& & Universitas Kristen & \\
& & Krida Wacana & \\
& & (UKRIDA) & \\
& &
\end{tabular}

Sumber: Hasil Pelaksanaan (2021)

\section{Hasil dan Pembahasan}

Hasil dari kegiatan abmas ini adalah siswa-siswi smk pelita IV dengan peserta berjumlah 40 orang guru dan 108 siswa semakin tertarik untuk menekuni wirausahaan khususnya dibidang digital printing dan pengelolaan hasil pangan (tata boga) dengan dibuktikan adanya kelompok kelompok kecil siswa dalam satuan tugas untuk membentuk kelompok wirausaha, serta berlangsung dengan sangat baik kegiatan tersebut, hal itu tergambar dari antusias peserta saat mengikuti hal tersebut.
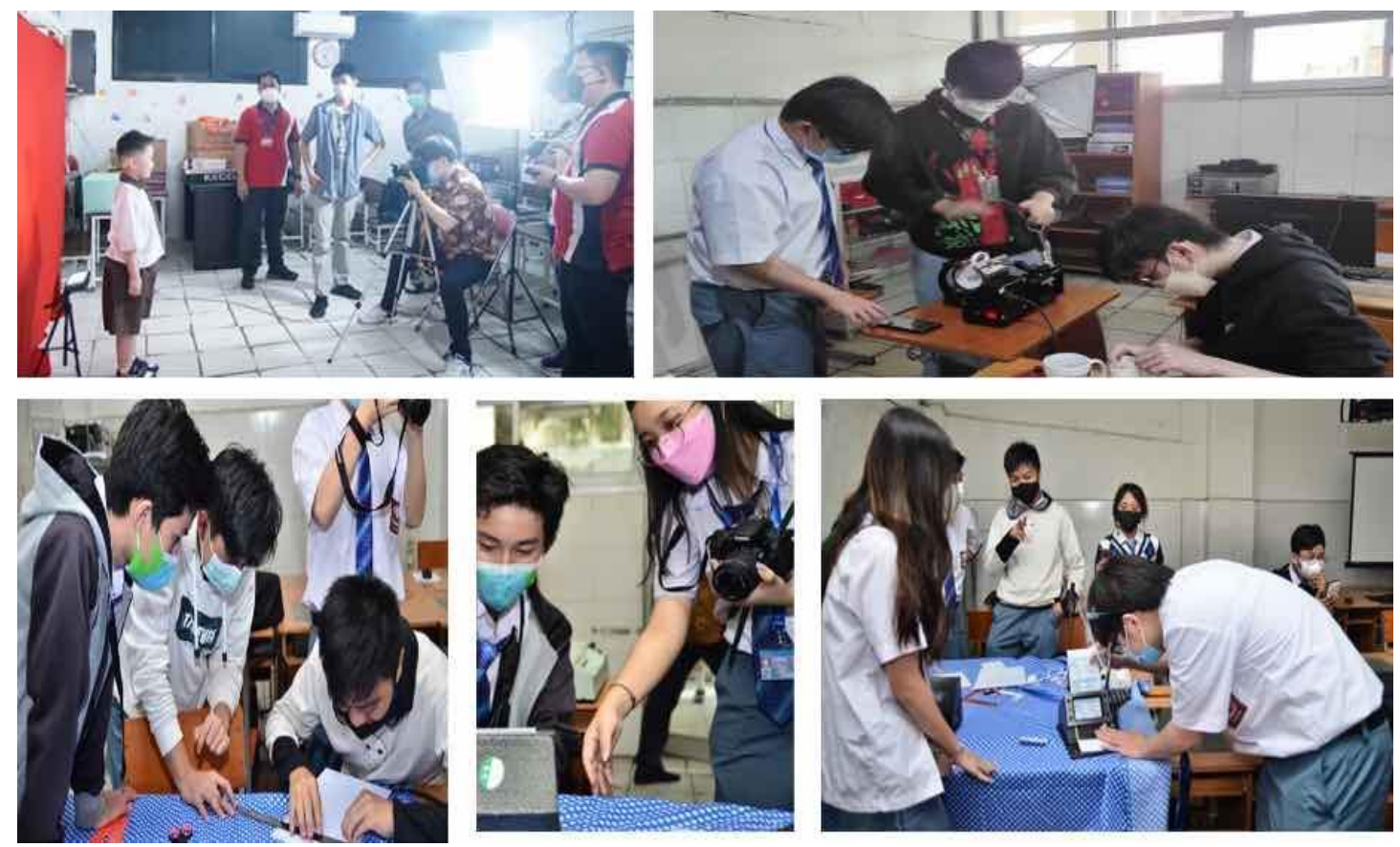

Sumber: Hasil Pelaksanaan (2021)

Gambar 1. Kegiatan Multimedia \& Digital Print 
Hasil pengabdian kepada masyarakat kelurahan Tanjung Duren Utara Jakarta Barat memberikan pemahaman tentang pentingnya peranan ekonomi rumah tangga. Ekonomi rumah tangga tidak hanya menjadi tanggung jawab suami, tetapi istri juga dapat berperan, workshop tentang kewirausahaan, mendorong peserta (masyarakat) mengenali potensi diri termasuk melihat peluang-peluang yang menghasilkan.
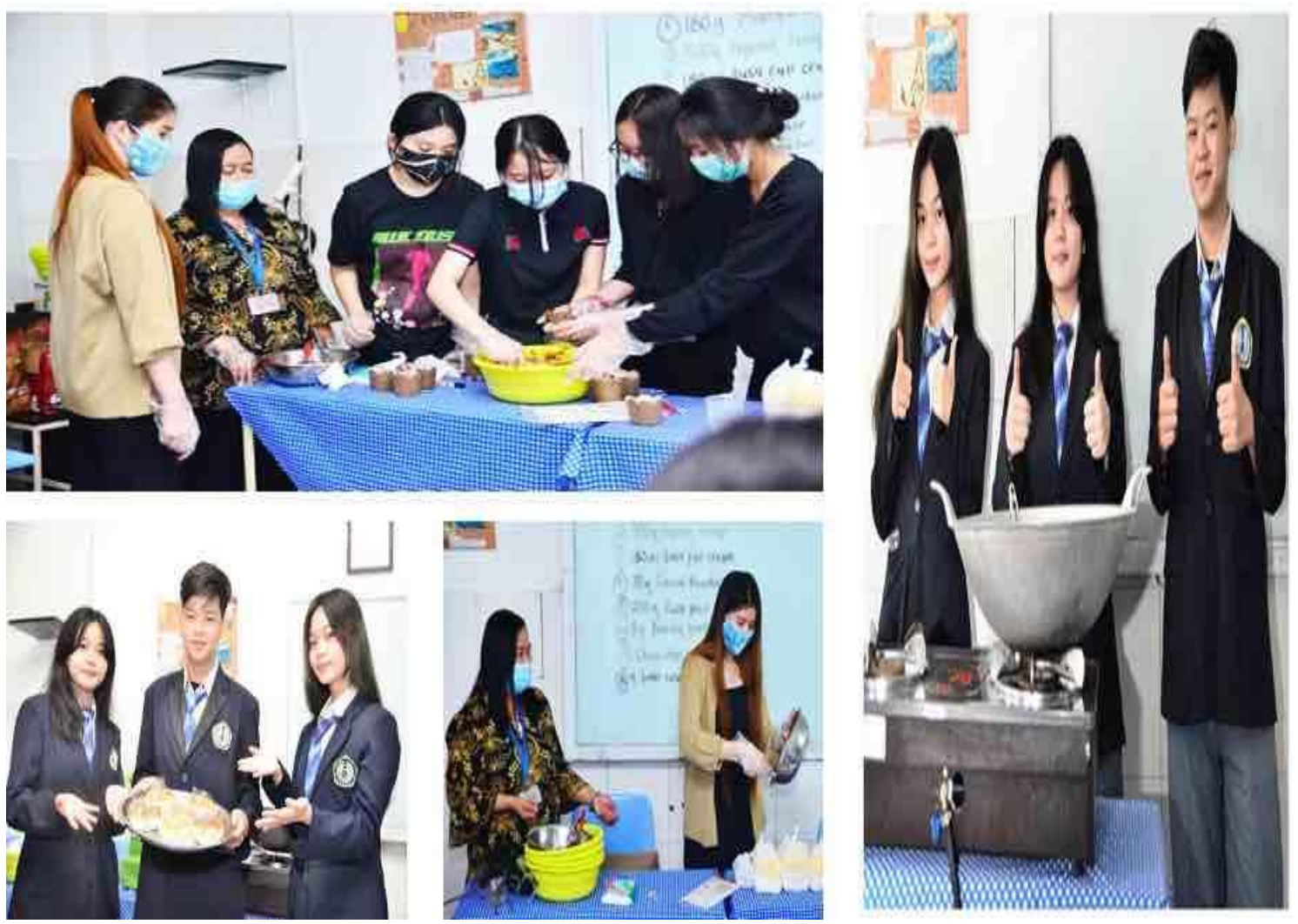

Sumber: Hasil Pelaksanaan (2021)

\section{Gambar 2. Kegiatan Tata Boga}

Melalui adanya pelaksanaan Pengabdian Kepada Masyarakat MBKM tersebut, hal ini memberikan solusi atas permasalahan yang dihadapi oleh mitra, yaitu adanya peningkatan lifeskill, yaitu kemampuan dalam peningkatan pengetahuan maupun penggunaan teknologi yang relevan dengan bidang usaha yang diajalani. Terkait ini, maka program pendampingan Abmas tersebut perlu dilakukan secara berkelanjutan (sustainability) guna memperluas cakupan mitra di locus yang lain.

Kendala yang ada, seperti perlu adanya dana pendamping mitra yang perlu terus diupayakan, yang sudah diinisiasi oleh Program Hibah IKU7 tersebut. Hasil keluaran ini menjabarkan tentang berbagai tahapan yang telah dilakukan dengan mencantumkan hasil/target yang sudah didapatkan yang dilengkapi dengan dokumentasi kegiatan (foto kegiatan, gambar alat peraga, foto produk dan sejenisnya).

Manfaat yang diperoleh (Kontribusi pada sektor ekonomi, sosial, dan lainnya) terkait manfaat kontribusi pelaksanaan program MBKM terhadap sektor ekonomi, sosial, dan lainnya. Dapat menjelaskan analisis Dampak Ekonomi dan Sosial terhadap implementasi 8 IKU MBKM. 

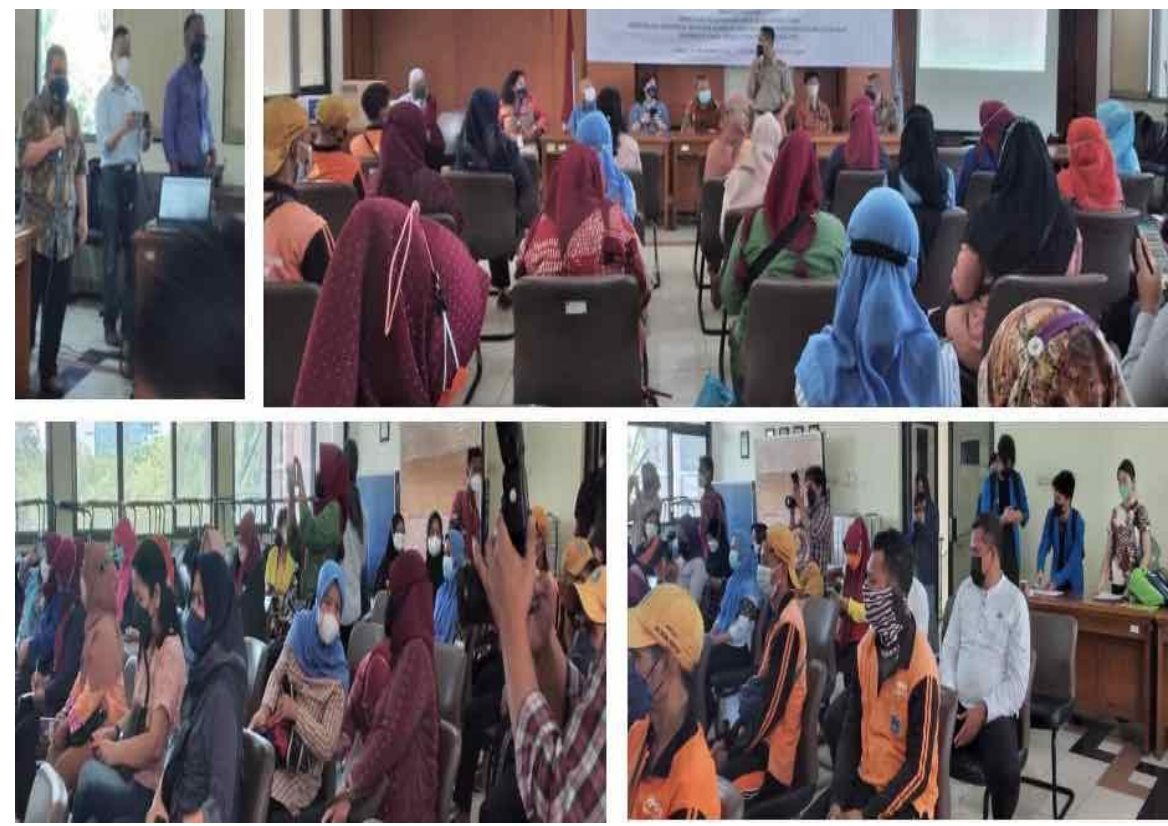

Sumber: Hasil Pelaksanaan (2021)

Gambar 3. Kegiatan Kelurahan Tanjung Duren Utara Jakarta Barat

Kegiatan Peningkatan Kapasitas Life Skill Pada Program Kewirausahaan Siswa SMK Pelita IV dan Kelurahan Tanjung Duren Utara dapat dikatakan sukses serta lancar dengan melihat respon peserta yang cukup baik dengan berikut hasil rekap feedback kuesioner yang kami berikan sebagai berikut:

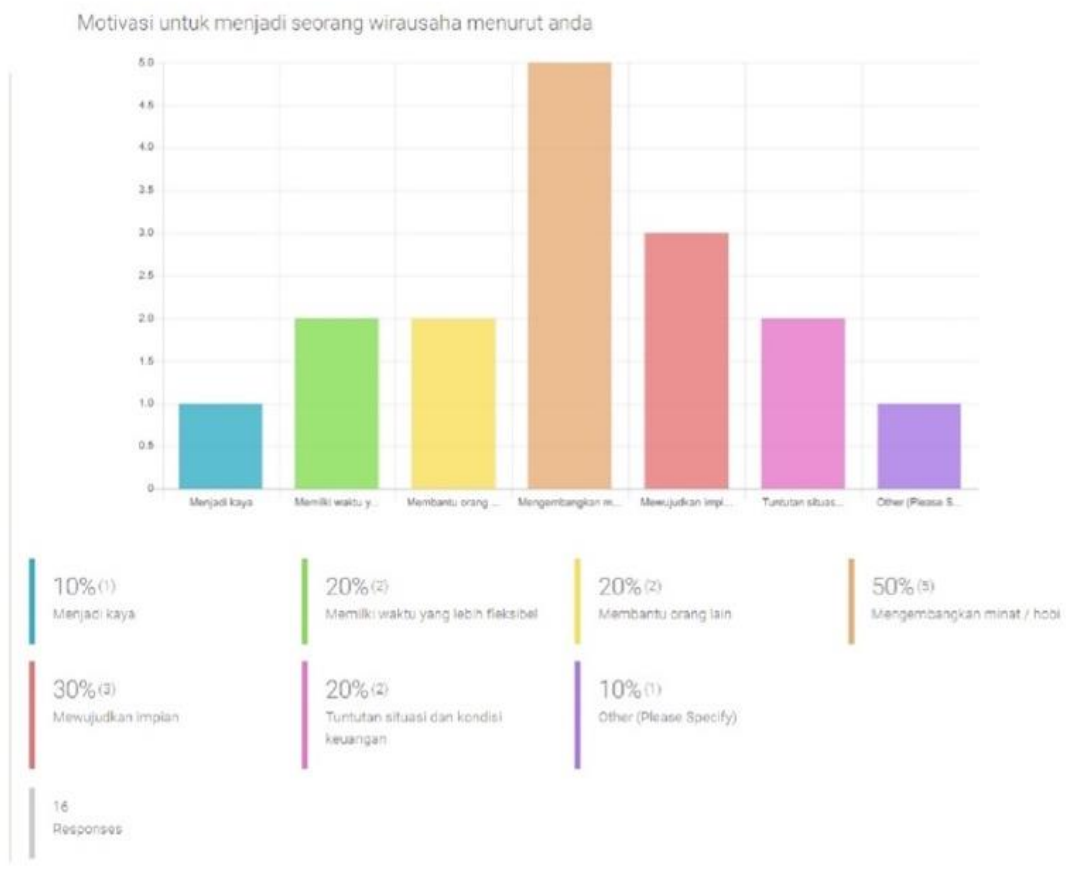

Sumber: Hasil Pelaksanaan (2021)

Gambar 4. Motivasi menjadi Wirausaha 
Saparso, Melitina Tecoalu, Bambang Siswanto, Krisnawati Tarigan, Daniel Widjaja, Rita Amelinda, Olfien Riruma, Hery Winoto Tj

Dari Motivasi menjadi wirausaha $50 \%$ responden menyatakan dapat mengembangkan minat/hobinya, 30\% responden dapat mewujudkan impiannya, $20 \%$ responden tuntutan kondisi keuangan dan waktu yang fleksibel.

\section{Seberapa antusias anda dengan pelatihan kewirausahaan yang diberikan}

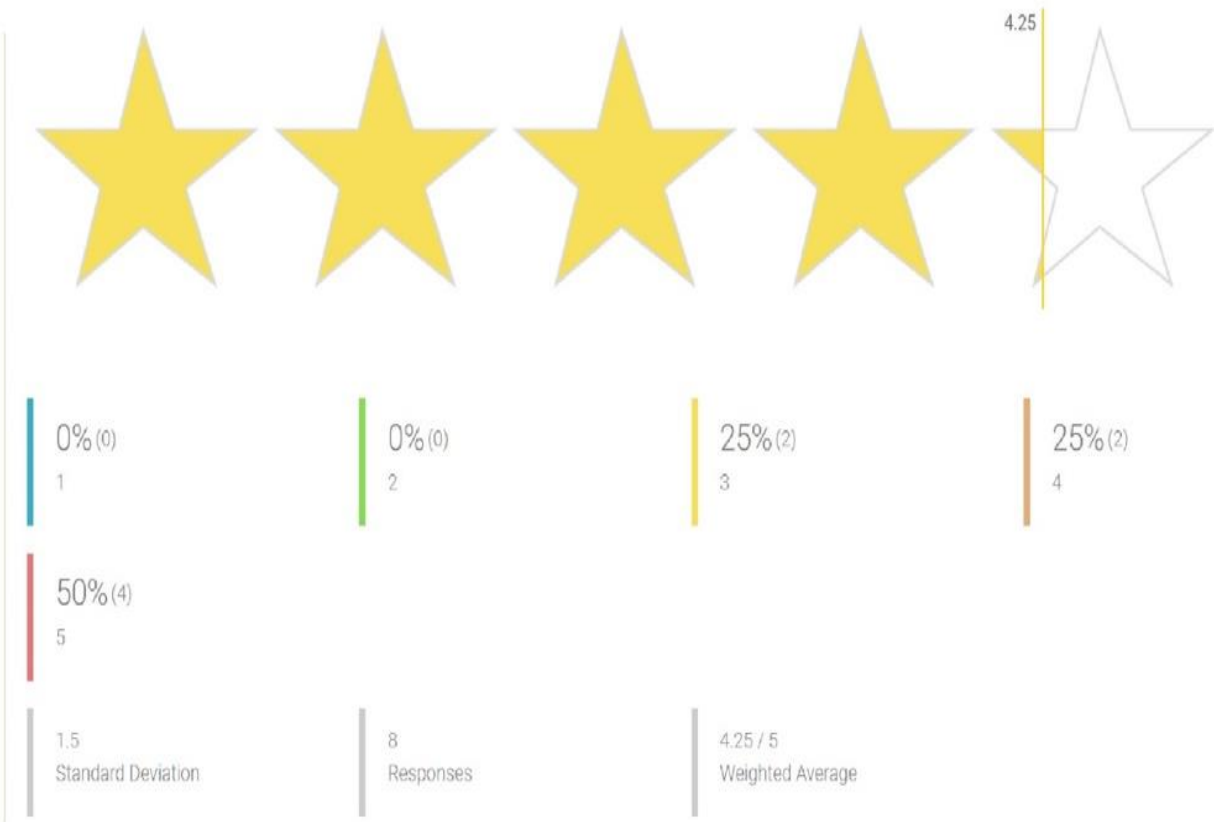

Sumber: Hasil Pelaksanaan (2021)

Gambar 5. Antusias terhadap pelatihan kewirausahaan

Sedangkan untuk Antusias terhadap pelatihan kewirausahaan hampir keseluruhan responden menjawab pada peringkat 3 sampai 5 yang terlihat antusias yang baik dan dapat terus dikembangkan.

\section{Apakah anda siap untuk menjadi seorang Wirausaha?}
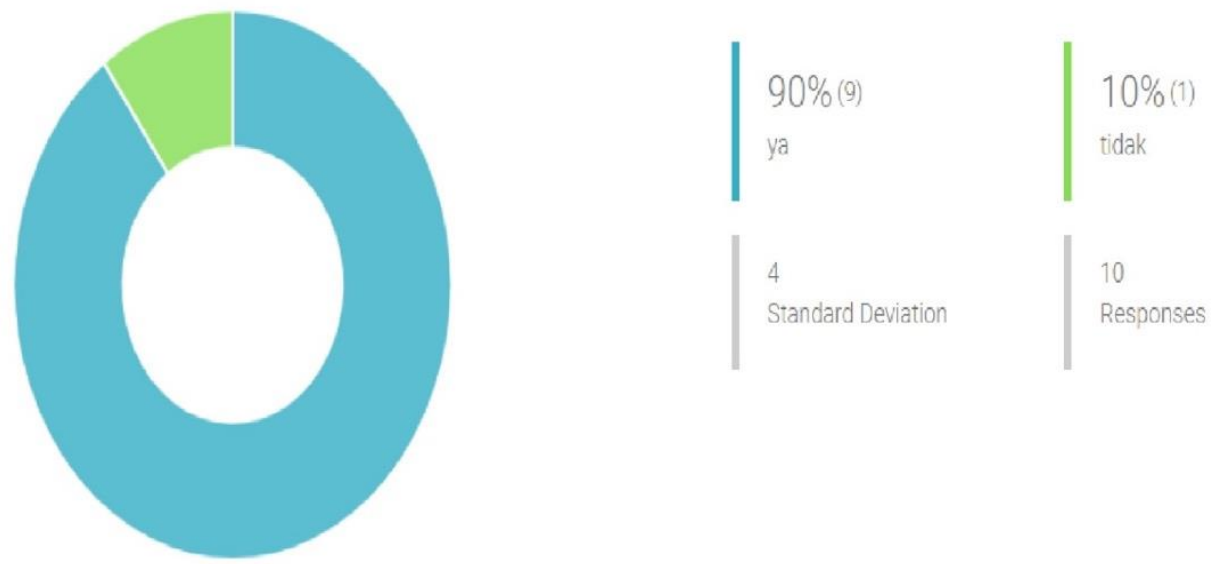

Sumber: Hasil Pelaksanaan (2021)

Gambar 6. Kesiapan menjadi seorang wirausaha 
Dari kesiapan para responden/peserta abmas terlukis sangat siap untuk memulai menjadi wirausaha pada masa yang akan datang.

\section{Kesimpulan}

Semua proses telah diimplementasikan bahwa kegiatan Peningkatan Kapasitas Life Skill Pada Program Kewirausahaan Siswa SMK Pelita IV dan Kelurahan Tanjung Duren Utara dapat dikatakan sukses serta lancer. Dari Motivasi menjadi wirausaha $50 \%$ responden menyatakan dapat mengembangkan minat/hobinya, 30\% responden dapat mewujudkan impiannya, $20 \%$. Untuk antusias terhadap pelatihan kewirausahaan hampir keseluruhan responden menjawab pada peringkat 3 sampai 5 yang terlihat antusias yang baik dan dapat terus dikembangkan.

\section{Ucapan Terima Kasih}

Ucapan terima kasih dan apresiasi kami berikan kepada semua pihak yang terlibat dalam implementasi kegiatan Hibah Dikti Program Penelitian Implementasi Kebijakan MBKM dan Pengabdiaan Kepada Masyarakat Berbasis Hasil Penelitian dan Purwarupa PTS, Kepada pihak SMK Pelita IV Jakarta dan Kelurahan Tanjung Duren Utara Jakarta Barat, serta semua pihak yang terlibat yang tidak dapat kami sebutkan satu per satu.

\section{Daftar Pustaka}

A. Indra S, A. Brilianta, W. D. Pertiwi, and H. Hartono, "Pendampingan Pengembangan Kreativitas UMKM Melalui Inovasi Produk Oatmeal Madu pada UMKM Body Scrub," Patria, vol. 1, no. 1, p. 19, 2019.

Dewi, L., Yani, A., \& Suhardini, A. D. (2015). Model Pendidikan Karakter dan Kewirausahaan Berbasis Etnopedagogis di Sekolah Dasar Kampung Cikondang. MIMBAR, Jurnal Sosial Dan Pembangunan, 31(2), 399. https://doi.org/10.29313/mimbar.v31i2.1480

Joni Heriansyah, Rustuyarso, Bambang Genjik, "Pengaruh Mata Pelajaran Kewirausahaan Terhadap Minat Berwirausaha Siswa SMA Negeri 1 Sungai Ambawang, IKIP Pontianak, joniheriansyah3@gmail.com

L. Halim and Y. I, "Strategi Pelatihan Hidroponik Sebagai Pemberdayaan Masyarakat Yang Bernilai Ekonomis," Patria, vol. 1, no. 2, p. 69, 2019

Ma and J. Tan, "Key components and implications of entrepreneurship: A 4-P framework," J. Bus. Ventur., vol. 21, no. 5, pp. 704-725, 2006.

Melitina Tecoalu, Hery Winoto Tj, Soegeng Wahyoedi, Saparso, Oktavia, Subagyo, Daniel Widjaja, Gatot Gunarso, Fredella Colline, Dwi Aprillita, \& Oki Sunardi. (2021). Pelaksanaan Abdimas Pembekalan Digital Marketing Bagi Jemaat GKI. Sendimas 2021 - Seminar Nasional Pengabdian Kepada Masyarakat, 6(1), 118-123. https://doi.org/10.21460/sendimasvi2021.v6i1.34

M. Wibowo, "Pembelajaran Kewirausahaan dan Minat Wirausaha Lulusan SMK," Eksplanasi, vol. 6, no. 2, pp. 109-122, 2011.

Nagel, P. J. F. N. (2016). Pengembangan Jiwa Dan Kecerdasan Wirausaha Untuk Kemandirian 
Saparso, Melitina Tecoalu, Bambang Siswanto, Krisnawati Tarigan, Daniel Widjaja, Rita Amelinda, Olfien Riruma, Hery Winoto Tj

Bangsa. Seminar Nasional IENACO, 2337-4349, 576-582.

Saparso et al., Spirit of Entrepreneurship: Pengetahuan Kewirausahaan. Jakarta: Ukrida Press, 2017.

Suryana, Kewirausahaan:kiat dan proses menuju sukses. Jakarta: Salemba Empat, 2013.

Suarjana, A. A. G. M., \& Wahyuni, L. M. (2017). Faktor Penentu Minat Berwirausaha Mahasiswa (Suatu Evaluasi Pembelajaran). Jurnal Bisnis Dan Kewirausahaan, 13(1), 11-22. https://doi.org/10.31940/jbk.v13i1.687 